\title{
The contribution of family doctors to primary care research: a global perspective from the International Federation of Primary Care Research Networks (IFPCRN)
}

\begin{abstract}
John W. Beasley University of Wisconsin Medical School, USA, Susan Dovey Australian Primary Health Care Research Institute, Australian National University, Canberra, Australia, Leon N. Geffen Chairperson of the Southern African Sentinel Practitioners Research Network (SASPREN), Francisco J. Gómez-Clavelina Autonomous University of Mexico and the Academy of Professors of Family Medicine of Mexico, Cynthia L. Haq University of Wisconsin School of Medicine, USA, Victor Inem Lagos University Hospital and the Institute of Child Health and Primary Care College of Medicine, University of Lagos, Lagos, Nigeria, Cindy L.K. Lam Family Medicine Unit, Department of Medicine, University of Hong Kong, China, Azhar Nugmanova Department of Family Medicine, Almaty Postgraduate Institute for Physicians, Almaty, Kazakhstan, Danica R. Pavlic Department of Family Medicine, Medical Faculty, University of Ljubljana, Slovenia, Waris Qidwai Aga Khan University, Karachi, Pakistan and Chris van Weel University Medical Centre, Nijmegen, The Netherlands
\end{abstract}

\begin{abstract}
The need for research that is applicable to the most common health problems is well recognized. Some of this research will be in the area of primary care, and family doctors must contribute to the research for it to be effective in improving care. Using a sample of key informants from 10 different countries, this paper explores the extent to which family doctors are involved in research in the various regions of the globe. We find great variability in the level of research being conducted by family doctors at academic institutions and in the development of the community research structures, such as practice based research networks. Despite the problems, family doctors are involved in research in every region assessed, and there is room for optimism that this role will be substantially expanded.
\end{abstract}

Key words: family practice; general practice; international; primary care; research; research networks

\section{Introduction}

It is well recognized that primary health care is critical to the provision of effective health care both in western countries (Starfield, 1991; Macinko et al., 2003) and in all regions of the world (Jong-Wook, 2003; World Health Organization, 2003). Family doctors are a critical component of the primary health care systems in the United

Address for correspondence: John W. Beasley, MD, University of Wisconsin School of Medicine, 777 South Mills Street, Madison, WI, USA. Email: jbeasley@fammed.wisc.edu Note on terminology: In this article the term 'family doctors' refers to the medical doctors called either family physicians or general practitioners in various countries and the term 'family medicine' refers to the discipline embraced by these practitioners.
States (Green et al., 2001) and in many countries. Studies of the ecology of health care highlight the similarities in the care delivered by family doctors under different health care systems (van Weel et al., 1995). Their emerging role, and that of their academic discipline of family medicine, has recently been described (Haq et al., 1995; Boelen et al., 2002).

There is a relative paucity of research about common problems and problems that are identified and treated in the primary care sector. Only about $10 \%$ of the world's research resources are directed at the $90 \%$ of the health problems faced by the world's population - problems which are often addressed in the primary care sector of health care. This has been referred to as the '10/90 gap' (Global Forum for Health Research, 2002). This disproportion of research funding 
(and thus research effort) has been recently been reiterated (Flanagin and Winkler, 2003).

For the research about problems addressed in primary care to be meaningful and relevant, that research is best done in primary care settings. Primary care research can succinctly be described as 'research done in a primary care context' and includes (in five categories which may overlap somewhat) basic research to develop research methods in the discipline, clinical research to inform clinical practice, health services research to improve health service delivery, health systems research to improve health systems and policies and educational research to improve education for primary care clinicians (Starfield, 1996; Mold and Green, 2000). The research in primary care that has been produced by family doctors - and its future potential - has tended to be undervalued both inside and outside primary care (van Weel and Rosser, 2004). Full participation in the development of a more complete research base for primary care is a challenge for family doctors worldwide (van Weel, 1999).

This article provides an overview of the contributions of family doctors and the academic discipline of family medicine to primary care research in selected regions of the world. Family doctors are playing a greater role in addressing the gap in primary care research, and there is increasing recognition that research not only about but also within primary health care is essential to improve clinical practice, service delivery, and health systems in all countries (Starfield, 1996; Berwick, 2003; van Weel and Rosser, 2004). Primary care clinicians, including family doctors, encounter health problems less frequently seen or managed in other sectors of health care. Clinical decisions are made in an environment of low probability of major disease and with the concurrent management of multiple problems (Beasley et al., 2004). For this reason, clinical research carried out by others in other settings and specialties has only limited relevance (Tilyard and Dovey, 2002). Recognizing the need for family doctors to be involved in all areas of the world, the World Organization of Family Doctors (WONCA), which was founded in 1972, is working to develop a coherent policy to promote family medicine research (van Weel and Rosser, 2004).

As family doctors increase their contributions to primary care research, the potential for inter- national cooperation in research increases. The effectiveness of international cooperation has been demonstrated by the development of the information base for understanding medical errors (Dovey, 2002) and evidence-based medicine in, for example, Slovenia (Svab et al., 1999). The international exchange of research ideas and expertise brings these ideas and skills to areas where they have been lacking and helps to break down isolation.

The history of family medicine in nearly every country is that it started from a model of general physicians without further specialized training following medical school. Around 1970, formal post-medical school training in family medicine was established in Australia, Canada, The Netherlands, New Zealand, the United Kingdom, the US, and the former Yugoslavia. These programmes recognized the need for specific training for family doctors and paved the way for education in family medicine to become a formal part of medical education at all levels. Although this also brought research to the agenda, priority had to be given to political survival and clinical training. Countries and regions have differed in the speed with which they have been able to move beyond these first priorities to add research, but the basic pattern is the same: in all countries with research programs - including research training and other capacity building programmes - these have been mainly a feature of the later stages of development. Both because of these historical facts and factors related to selection of students, family doctors have generally been more clinically than research oriented.

There are substantial differences in the research training and experience of family doctors in different countries, and this is related to differences in medical education. While in the US and Canada students enter medical school for 4 years of 'post-graduate' training after completing college ('undergraduate') education, most other countries have students entering medical school immediately upon completion of secondary education. This leads to differences in scientific orientation and background. Additionally, there are differences in post-medical school training with, for example, two years of vocational training for family medicine in Canada and three in most other countries. The expectation for trainees' participation in research training also differs. 
For example, in The Netherlands research is an integral part of the training program and is part of the trainee's assessment and one track provides protected time for $\mathrm{PhD}$-directed education. In most areas of the world there are steps towards the development of additional training in primary care research, including official recognition of this education in the form of a Masters or other advanced degree.

\section{Methods}

A convenience sample of key informants representing several areas of the world were contacted by the lead author and asked to respond to questions about the status of research in academic family medicine, the status of practice-based primary care research networks, the productivity of primary care research and the prospects for primary care research. Responses were received from all the informants contacted. The informants were from Australia and New Zealand, Hong Kong, the former Yugoslavia, Kazakhstan, Mexico, The Netherlands, Nigeria, Pakistan, South Africa and the US. In each case, the informant was asked to comment not only on his or her specific country, but the region as well. After extraction from each report, the overall assessment was reviewed by each of the authors.

\section{Results}

\section{The status of research in academic family medicine}

In many countries, the participation of family doctors in primary care research originated as much outside traditional academic settings as within them. For example both national organizations such as the Royal College of General Practitioners in the UK, the Royal New Zealand College of General Practitioners, post-graduate training programs, and semi-autonomous research groups such as the Ambulatory Sentinel Practice Network in the US have played major roles. However, the focus in this article will be on the involvement of family doctors in research in the academic setting.

The development of academic family medicine and its support of research in different countries can be categorized into three broadly defined stages. Countries in the first stage are those where formal family medicine education and training has existed in most medical schools for 20 years or more. Countries in the second stage are those where it has existed in some for 10 years or more. Countries in the third stage are those where family medicine is just emerging as an organized discipline within medical schools. In general, strong academic departments are a necessary, although certainly not sufficient, condition for the development of research. Even in countries with a history of strong academic departments (e.g. Mexico) family doctors have only recently become involved in research. Even in first stage countries family doctors may be failing to utilize the opportunities for research (Graham et al., 2002).

As examples of the first stage, in Australia, Canada, Denmark, Mexico, New Zealand, South Africa, The Netherlands, the UK, the US, and the former Yugoslavia nearly all medical schools have had formal academic departments of family medicine for most of the last 20 or more years, in some countries (e.g. the former Yugoslavia) these existed as part of other departments, such as public health, and not as independent departments of family medicine, although formal post-graduate training for family doctors had been in place since 1961 .

In the second stage are countries such as Germany and France where academic family medicine is a more recent development. Also in this category are Hong Kong SAR, Taiwan and Kazakhstan, where there are new formal units of academic family medicine in all medical schools. In these countries the level of training for research is variable and resources are limited.

Some EU countries (e.g. Italy and Spain) are just beginning to have academic departments and are in the third category along with a substantial part of the world, including mainland China, Pakistan and the Indian subcontinent and Africa (with the exception of South Africa), where academic departments of family medicine are just emerging. For example, in Nigeria although the specialty of general medical practice was established in 1970, of the 17 medical schools, only three have family medicine departments and two others have some quasi-departmental status. Uganda has two departments of family medicine. Latin America is experiencing slow progress 
(Knox et al., 2003). In many areas of the world, war and civil unrest have made development very difficult (Morikawa, 2003).

Even in countries where academic departments are just emerging, research is often an integral part of the advanced trainee's education. As an example, the restructuring of health care systems has been an important factor in bringing family medicine to university status, as is illustrated in Central and Eastern Europe, the Central Asia republics and the Commonwealth of Independent States. However in the academic departments in these countries there is a lack of trained family doctor researchers and thus the research activities that involve family doctors often rely upon support and mentoring from cooperating specialists in other areas.

In many areas of the world, research training is more common for advanced trainees than it is in the US and Canada where the training is more directed at vocational skills. Building a research infrastructure and staff with protected time for grant writing and research time takes resources and planned promotion (van Weel and Rosser, 2004). In some first stage countries, especially the UK and The Netherlands, this has been successfully achieved and departments of family medicine are able to compete for, and co-operate in, major grant programs. However, in most other countries primary care research in academic departments is only beginning or has had stunted development, and departments of family medicine have great difficulty acquiring significant research grants to support faculty and staff time to support research. Even in the United States only about $10 \%$ of the departments of family medicine have significant research support from large federal research grants.

\section{The status of practice-based research networks}

A critical element in primary care research is the linkage between academic departments and practices in the communities to make available a 'laboratory' for primary care research. These linking organizations often take the form of practice-based research networks (PBRN). PBRN are generally considered to be groups of clinicians who participate in the governance of the network, the selection of the research questions, the design of the projects and who have a group identity that extends beyond any one project. Most definitions exclude groups of clinicians who simply provide data for studies without having any input into the project. The building of PBRN is a key factor in the development of primary care research (van Weel and Rosser, 2004). Primary care research networks have proved to be a powerful tool to answer questions about common problems, to stimulate interest in research, and to link community physicians with academic colleagues (Nutting et al., 1999; van Weel et al., 2000; Green and Dovey, 2001; Thomas et al., 2001; Berwick, 2003).

Canada, The Netherlands, UK and the US have established multiple research networks variably supported by academic institutions and professional organizations. In the US, the value of these networks has been recognized by the American Academy of Family Physicians who have established their own national network by the Federal Agency for Healthcare Quality and Research which is providing limited supporting funds to PBRN. The progress of PBRN in the UK has recently been reviewed (Wilson, 2004).

A number of networks have arisen in Australia and New Zealand, although in New Zealand there have been major problems with sustainability and the models tended to be more of 'top down' governance than governance with active input from the network members. The Australian government's recent investments in primary care research have supported several new PBRN (Gunn, 2002).

In the EU, the European General Practice Research Network, while not actually a PBRN, has representatives from 28 EU countries with substantial expansion planned. However, there are fewer smaller PBRN in the EU. In Hong Kong, although over 200 family doctors have participated in projects there is no active network. South Africa has the South African Sentinel Practice Research Network which has been quite active in epidemiologic research (De Villiers and Geffen, 1998). Elsewhere, the situation is less advanced. Nigeria has one, but no others are known on the African continent, nor are there any in the Indian subcontinent. Kazakhstan is considering starting one.

A more recent development is that of linkages of networks into 'federations' of networks, including the US Federation of Practice Based 
Research Networks with 36 full member networks (and 51 total networks) which is supported by the American Academy of Family Physicians (American Academy of Family Physicians, 2004), and the UK Federation of Primary Care Research Networks which has over 40 members (Smith, 2000) and is supported by the UK Department of Health research and development funds. More recently, the World Organization of Family Doctors (WONCA) has sponsored the development of the International Federation of Primary Care Research Networks (IFPCRN) (IFPCRN, 2004). The membership of the IFPCRN includes both functioning networks and also individuals who are interested in starting networks or in network research. All three of these organizations have the general goals of facilitating communication between networks, providing mutual support and advocacy, and helping to build capacity. Like their network members, however, funding is limited and they mostly rely on volunteer work for their maintenance.

\section{Primary care research productivity}

Primary care research by family doctors is accomplished both in academic institutions and in networks. A very few selected examples of research by family doctors are listed below to give a sense of the scope of their activities. The examples are organized by the five, partially overlapping, categories of primary care research (Starfield, 1996; Mold and Green, 2000).

\section{Basic research (research into methods)}

There have been analyses of the costs of research in the United States (Beasley, 2000), and the members of the European General Practice Research Network have conducted research on the information obtained from primary care (Fleming and Pavlic, 1998). Researchers in Hong Kong have explored the use of the SF-36 in Chinese patients (Lam, 2003).

\section{Clinical research (research to inform clinical practice)}

Family doctors in Australia and New Zealand have published studies on the treatment of common conditions (MaGPIe Research Group, 2003), asthma care (Glasgow et al., 2003). European doctors have published on diagnostic uncertainty
(Green and Holden, 2003). Physicians in Hong Kong have published studies on morbidity patterns in primary care (Lee et al., 1995; Munro et al., 1991) and patient-centred health outcome measures (Lam, 1995; Lam and Lauder, 2000). The South African Sentinel Practice Research Network has published studies on domestic violence (De Villiers, 1998; Marais et al., 1999) and health surveillance (De Villiers and Geffen, 1998). Some of the clinical research conducted in PBRN in the US has been recently summarized (Nutting et al., 1999).

\section{Health services research (research to improve health service delivery)}

The Australian and New Zealand researchers have explored issues in time management in practice (Buetow et al., 2002) and those in Mexico have published findings relating to family assessment tools and systematic models of family practices (Gomez-Clavelina and Irigoyen-Coria, 1995; Gomez-Clavelina et al., 1999). Researchers in Pakistan have explored the role of unsafe injections in the transmission of hepatitis B infection (Usman et al., 2003) and completed studies relating to physician-patient communication (Qidwai, 2003a; Qidwai et al., 2003b).

\section{Health systems research (research to improve health systems and policies)}

Researchers in Kazakhstan have explored issues of health systems development including the gender gap in health care utilization (Cashin et al., 2002b) and the impact of primary health care on hospitalization (Cashin et al., 2002a). Nigerian family doctors have conducted studies on reproductive health issues and the prevention of mother to child transmission of HIV (Inem et al., 2002; 2003). Pakistani researchers have explored the problem of elevated lead levels in children (White et al., 2001), which led to measures to reduce environmental pollution, as well as studies of health services utilization (Qidwai et al., 2003a).

\section{Educational research (research to improve education for primary care clinicians)}

Family doctors in Mexico have published on research training (Irigoyen-Coria et al., 2000; Olaya-Vargas et al., 2000) in Hong Kong about the impact of clerkships (Dixon et al., 2000), in Pakistan on feedback in education (Qidwai, 
2003), and in the US on the effectiveness of rural education for primary care physicians (Beasley et al., 1992). The Netherlands School of Primary Care Research $(\mathrm{CaRe})$ as a centre of excellence combines clinical research on primary care health problems, health systems research and research on the quality of care under optimal conditions of collaboration to develop research methodologies (Netherlands School of Primary Care Research, 2004).

When primary research studies are completed, there are problems in many countries getting the results published. For example, there are 40 Indian medical journals listed in Index Medicus, but none are directed towards primary care research. Even in the US there are only three indexed journals directed towards the work of family doctors, although many family doctor researchers publish elsewhere.

\section{Prospects for family doctors contributing to primary care research}

Despite the problems, there are a number of hopeful developments that indicate increased support for research by family doctors may be coming. First, as described above, countries in nearly all regions of the world are beginning to incorporate family medicine into their formal education programs and research training is often a component of this education.

Secondly, at national levels a number of countries are recognizing the need to support primary care research. Australia has tackled the problem head on, making an investment of $\$ 50$ million over five years to build research capacity in general practice and primary health care (Gunn, 2002). In the US and the UK, at least a small proportion of research funding has been made available to support primary care research, and this has increased the funding available to family doctors to conduct primary care research. There has recently been a proposal in the US for the formation of a publicprivate partnership that would devote $0.25 \%$ of the budgets of all stakeholders to clinical (if not primary care) research (Crowley, 2004).

In Scotland, the Scottish School of Primary Care (SSPC) has been able to stimulate a substantial increase in research (Wyke et al., 2000; Sullivan et al., 2002; Scottish School of Primary Care, 2004). In The Netherlands, the invest- ment in family medicine research through the Medical Research Council 1985-1992 has resulted in a substantial increase in (PhD level) research output, leading to a strengthening of the evidence base of family practice. As a consequence, special funding for problems in primary care is now integrated in the structure of Dutch health research, and leading primary care researchers have established a centre of excellence - the Netherlands School of Primary Care Research (CaRe) that is able to compete with other biomedical research collaborations.

Thirdly, it is being recognized that international cooperation has the potential to influence national developments and promote an investment in primary care research. Contacts between the SSPC and the CaRe have resulted in the Brisbane Initiative to strengthen advanced research training (van Weel, 2003). Currently, leading groups from Australia, Belgium, Germany, The Netherlands, the UK and the US are participating in this initiative (van Weel, 2003). Co-operation across international boundaries for research have made it possible to describe phenomena or answer clinical questions that would be difficult to answer within one country (Beasley, 1993; Culpepper and Froom, 1988; Grol et al., 1997; Svab et al., 1999; Makeham et al., 2002; Okkes et al., 2002).

Finally, international agencies, such as the World Health Organization (WHO), are beginning to recognize the need for a new initiative in primary care research as a way to meet the above-mentioned 10/90 gap (Jong-Wook, 2003). The potential for the WHO to stimulate and support primary care research, and to support the involvement of family doctors as an integral part of that research is great. The success of the international research project on the cross-cultural validation of the COOP/WONCA charts was proof of the effectiveness of collaborative projects in training new researchers from countries where family medicine research is in its infancy (van Weel et al., 1995). Unfortunately, however, a recent WHO report on primary care fails to discuss in any detail the need for primary care research or the involvement of family doctors in the process (World Health Organization, 2003).

The Global Forum for Health Research may help to stimulate this effort (Global Forum for Health Research, 2002). The World Organization 
of Family Doctors (WONCA) through its task force on research, is turning increasing attention to stimulating the development of research. In particular, the founding and functioning of PBRN throughout the world is a WONCA priority, for which the International Federation of Primary Care Research Networks (IPFCRN) offers support.

Newer technologies should also prove very helpful. The ability to communicate via the Internet enables family doctor researchers, even in resource-poor countries, to collaborate with each other and with researchers in countries with greater resources. The increasing availability and reliability of relatively low cost technologies, such as personal digital assistants (PDA), and the ability to link these via cellular telephone technology opens opportunities to link clinical care, education and research even in resource-poor countries in Africa (SATELLIFE, 2003).

\section{Conclusions}

There are multiple challenges that family doctors will have to contend with in order to make their full contribution to primary care research. These include:

- Poor articulation of scope of primary care research

- Misallocation of resources (10/90 gap)

- Funding sources tend to fund disease specific research and focus on biomedical technologies

- Research seldom leads to biomedical breakthrough or financial gain and is thus undervalued

- Historical focus on research about rather than within primary care

- Historical role of family doctors did not include research

- Lack of culture and/or expertise among many family doctor academicians

- Lack of formal training programs (or expectations) - training is mainly directed at vocational skills

- Difficulties involving community family doctors in research despite necessity of conducting research involving those physicians

- Frequent 'top down' approach (as in New Zealand)

- Few venues for publication.
At the same time, there has been considerable progress in all regions of the world. This progress includes:

- Recognized need for research that makes a difference in care

- Recognition that research outside of primary care cannot alone provide a sufficient knowledge base for primary care

- Increased national and international funding both for infrastructure and for project grants

- Activation of family doctors internationally (e.g., Brisbane Initiative, Kingston Conference, IFPCRN)

- Activation of national family doctor groups (e.g. AAFP)

- Formation of networks of networks (e.g., US FPBRN, UK FPCRN, IFPCRN)

- Beginning of international collaborative studies

- Increasing numbers and extent of formal research training programs in nearly all countries

- Involvement of community family doctors in supporting academic research and through PBRN

- New technologies (e.g., SATELLIFE, internet)

The extent of the contributions of family doctors to the global primary care research enterprise, while progressing in most areas of the world, still falls short of that which is needed if we are to optimize the health of our populations. This is true even in countries which are relatively rich in resources; the shortfall is even more notable in countries where resources are more limited. A critical mass of researchers and resources is an essential element for primary care research development and international collaboration is one way to promote further development. Family doctors need to look beyond national borders to develop additional methods to strengthen their participation in research.

Family doctors can make significant contributions to the resolution of the world's $10 / 90$ gap - and these contributions are essential to develop a badly needed research base in family medicine where the majority of health problems occur and are resolved. There is room for optimism that funding agencies will increase support for research by family doctors who are responsible for the care of most of the patients most of 
the time. There is also optimism that international support efforts being developed by WONCA and other organizations will support this research and that family doctors make increasingly important contributions to primary health care research around the globe.

\section{Acknowledgements}

The authors are indebted to Damilya Nugmanova, $\mathrm{MD}, \mathrm{PhD}$, Professor, Department of Family Medicine, Almaty Postgraduate Institute for Physicians, Almaty, Kazakhstan for additional contributions regarding research in the Central Asia Republics and to Mary Stone for critically important help with manuscript preparation.

\section{References}

American Academy of Family Physicians (AAFP). 2004: http://www.aafp.org/x19545.xml (retrieved 17 January, 2004).

Beasley, J.W. 1993: Lessons from the international primary care network. Journal of American Board of Family Practice 6, 419-20.

Beasley, J.W. 2000: Practice-based research in the United States. Primary Health Care Research and Development 1, 135-37.

Beasley, J.W., Vogt, S.C. and Murray, J.F. 1992: Can NBME scores distinguish students who choose a practice-based clerkship? Family Practice Research Journal 12, 185-91.

Beasley, J.W., Hahn, D., Wiesen, P., Plane, M.B. and Manwell, L. 2000: The cost of primary care research. The Journal of Family Practice 49, 985-89.

Beasley, J.W., Hankey, T.H., Erickson, R., Stange, K., Mundt, M., Elliott, M., Wiesen, P. and Bobula, J. 2004: How many problems do family physicians manage at each encounter? A WReN study. Annals of Family Medicine.

Berwick, D.M. 2003: Dissemination of innovations in health care. Journal of the American Medical Association 289, 1969-75.

Boelen, C., Haq, C., Hunt, V., Rivo, M. and Shahady, E. 2002: Improving health systems: The contribution of family medicine. WONCA. Singapore: The World Organization of Family Doctors.

Buetow, S., Adair, V., Coster, G., Hight, M., Gribben, B. and Mitchell, E. 2002: Qualitative insights into practice time management: does 'patient-centred time' in practice management offer a portal to improved access? British Journal of General Practice 52, 981-87.

Cashin, C.E., Borowitz, M. and Zuess, O. 2002a: The gender gap in primary health care resources utilization in Central Asia. Health Policy and Planning 17 (3), 264-72.
Cashin, C., Zuess, O., Nurbayev, A., Khe, N., Hafner, G. and Baiserke, M. 2002b: The impact of primary healthcare development on patterns of hospitalization: The case of integrated management of childhood illness (IMCI) in Karaganda City, Kazakhstan. Technical report. Karaganda, Kasakhstan: ABT Associates.

Crowley, W.F., Sherwood, L., Salber, P., Scheinberg, D., Slavkin, H., Tilson, H., Reece, E.A., Catanese, V., Johnson, S.B., Dobs, A., Genel, M., Korn, A., Reame, N., Bonow, R., Grebb, J. and Rimoin, D. 2004: Clinical research in the United States at a crossroads: a proposal for a novel public-private partnership to establish a National Clinical Research Enterprise. Journal of the American Medical Association 291, 1120-26.

Culpepper, L. and Froom, J. 1988: The international primary care network: purpose, methods and policies. Family Medicine 20, 197-201.

De Villiers, P.J.T. 1998: Home violence in South Africa. Surveillance during 1996 by SASPREN, a sentinel network of general/family practitioners. South African Family Practitioner Sept/Oct, 87-89.

De Villiers, P.J.T. and Geffen, L.N. 1998: The development of passive health surveillance by a sentinel network of family practitioners in South Africa. South African Medical Journal 88, 256-59.

Dixon, A.S., Lam, C.L.K. and Lam T.P. 2000: Does a brief clerkshop change Hong Kong medical student's ideas about general practice? Medical Education 34, 339-47.

Dovey, S. 2002: The LINNAEUS Collaboration - An international network for research on primary care quality. ICPRN Newsletter 31 (2), 3-6. http://groups.msn.com/ IFPCRN (retrieved 1 February 2004).

Flanagin, A. and Winkler, M.A. 2003: Global health - targeting problems and achieving solutions: a call for papers. Journal of the American Medical Association 290, 1382-84.

Fleming, D. and Pavlic, D.R. 1998: Information from primary care: its importance and value - A comparison of information from Slovenia and England and Wales, viewed from the 'Health 21' perspective. http://europa.eu.int/ comm/health/ph_projects/1998/monitoring/fp_monitoring 1998_frep_05_en.pdf (retrieved 17 January, 2004).

Glasgow, N.J., Ponsonby, A.L., Yates, R., Beilby, J. and Dugdale, P. 2003: Proactive asthma care in childhood: general practice based randomised controlled trial. British Medical Journal 327, 659.

Global Forum for Health Research. 2002: The 10/90 Report on Health Research 2001-2002. Global Forum for Health Research, c/o World Health Organization: Geneva.

Gomez-Clavelina, F.J. and Irigoyen-Coria, A. 1995: Two types of family assessment. Family Process 34, 363-64.

Gomez-Clavelina, F.J., Irigoyen-Coria, A., Ponce-Rosas, E.R., Teran-Trillo, M., Fernandez, O.M.A. and Yanez-Puig, E. 1999: Analisis comparativo de seis recomendaciones para el diseno de genogramas en Medicina Familiar. Archivos en Medicina Familiar 1, 13-20. 
Grol, R., Baker, R., Roberts, R. and Booth, B. 1997: Systems for quality improvement in general practice: a survey of 26 countries. European Journal of General Practice 3, 65-68.

Graham, R., Roberts, R.G., Ostergaard, D.J., Pugnano, P.A. and Green, L.A. 2002: Family practice in the United States: a status report. Journal of the American Medical Association 288, 1097-101.

Green, L.A. and Dovey, S.M. 2001: Practice based primary care research networks. British Medical Journal 322, $567-68$.

Green, C. and Holden, J. 2003: Diagnostic uncertainty in general practices. A unique opportunity for research? European Journal of General Practice 9 (1), 13-15.

Green, L.A., Fryer, G.E., Yawn, B.P., Lanier, D. and Dovey, S.M. 2001: The ecology of medical care revisited. The New England Journal of Medicine 344, 2021-2025.

Gunn, J.M. 2002: Should Australia develop primary care research networks? Medical Journal Australia 177, 63-66.

Haq, C., Ventres, W., Hunt, V., Mull, D., Thompson, R., Rivo, M. and Johnson, P. 1995: Where there is no family doctor: the development of family practice around the world. Academic Medicine 70, 370-80.

IFPCRN. 2004: http://groups.msn.com/IFPCRN (retrieved 17 January 2004).

Irigoyen-Coria, A., Hernández-Torres, I., Gómez-Clavelina, F.J., Ponce-rosas, R. and Monroy-Caballero, C. 2000: Fronteras de la investigación en medicina familiar. Archivos en Medicina Familiar 2 (4), 105-12.

Inem, V., Bamgbala, A.O., Ayankogbe, O.O., Roberts, A., Jarikre, A. and Grange, A. 2002: Reproductive health issues arising from a HIV seroprevalence study in a voluntary counseling and testing programme in a Nigerian refugee camp. Nigerian Medical Practitioner 42 (5), 28-33.

Inem, V., Adedokun, A.O. and Ayankogbe, O.O. 2003: Voluntary counseling and testing programme in the prevention of mother to child prevention of HIV in a practice based research network (PBRN) hospital in Lagos Nigeria. Nigerian Medical Practitioner 43 (6), 135-38.

Jong-Wook, L. 2003: Global health improvement and WHO: shaping the future. Lancet 362, 2083-88.

Knox, L., Ceitlin, J. and Hahn, R.G. 2003: Slow progress: predoctoral education in family medicine in four Latin American countries. Family Medicine 35, 591-95.

Lam, C.L.K. 1995: Health outcome of stroke patients in Hong Kong. Huisarts En Wetenschap 38, 129-31.

Lam, C.L.K. 2003: Reliability and construct validity of the Chinese (Hong Kong) SF-36 for patients in primary care. Hong Kong Practitioner 25, 468-75.

Lam, C.L.K. and Lauder, I.J. 2000: The impact of chronic diseases on the health-related quality of life (HRQOL) of Chinese patients in primary care. Family Practice 17, 159-66.

Lee, A., Chan, K.K.C., Wun, Y.T., Ma, P.L., Li, L. and Siu, P.C. 1995: A morbidity survey in Hong Kong, 1994. Hong Kong Practitioner 17, 246-55.

Macinko, J., Starfield, B. and Shi, L. 2003: The contribution of primary care systems to health outcomes within Organi- zation for Economic Cooperation and Development (OECD) countries 1970-1998. Health Services Research $38,831-65$.

MaGPIe Research Group. 2003: The nature and prevalence of psychological problems in New Zealand primary healthcare: a report on Mental Health and General Practice Investigation(MaGPIe). New Zealand Medical Journal 116, U379.

Makeham, M., Dovey, S., County, M. and Kidd, M. 2002: An international taxonomy for reporting general practice error in Australia and five other countries. Medical Journal of Australia 177, 68-72.

Marais, A., Moller, A.T., De Villiers, P.J.T. and Stein, D.J. 1999: Domestic violence in patients visiting general practitioners prevalence, phenomenology and association with psychopathology. South African Medical Journal 89, 635-40.

Mold, J.W. and Green, L.A. 2000: Primary care research: revisiting its definition and rationale. Journal of Family Practice 49, 206-208.

Morikawa, M.J. 2003: Primary care training in Kosovo. Family Medicine 35, 440-44.

Munro, C., Lewis, J., Lam, C. and Research Committee of the HKCGP. 1991: A survey of the referral patterns in Hong Kong. Hong Kong Practitioner 13, 1609-20.

Netherlands School of Primary Care Research (CaRe). 2004: http://www.researchschoolcare.nl (retrieved 9 March 2004).

Nutting, P.A., Beasley, J.W. and Werner, J.J. 1999: Practicebased research networks answer primary care questions. Journal of the American Medical Association 281, 686-88.

Okkes, I.M., Polderman, G.O., Fryer, G.E., Yamada, T., Bajak, M., Oskam, S.K., Green, L.A. and Lamberts, H. 2002: The role of family practice in different health care systems: a comparison of reasons for encounter, diagnoses and interventions in the primary care populations in the Netherlands, Japan, Poland and the United States. Journal of Family Practice 51, 72-73.

Olaya-Vargas, M.A., Gómez-Clavelina, F.J., Brambila, C., Rojo-Padilla, J.A. and Vernon, R. 2000: Consentimiento informado en usuarias de Métodos de Planificación Familiar en el ISSSTE, México. Archivos en Medicina Familiar 2 (3), 81-89.

Qidwai, W. 2003: Structured feedback from students in tutorial teaching. Journal of College of Physicians and Surgeons of Pakistan 13, 726-27.

Qidwai, W., Muhammad, B., Ali, S.S. and Ayub, S. 2003a: Patient complaints among emergency room patients at a teaching hospital in Karachi. Journal of Liaquat University of Medicine and Health Sciences 2, 50-52.

Qidwai, W., Karim, S.I. and Irfan, F.M. 2003b: Communication skills of family physicians in a doctor-patient consultation. Journal of College of Physicians and Surgeons of Pakistan 13, 674.

SATELlIFE Inc. SATELlIFE PDA Project: $h t t p: / / p d a$. healthnet.org/ (retrieved 15 December 2003).

Scottish School of Primary Care. 2004: http://www.sspc.uk. com (retrieved 9 March 2004) 
Smith, H. 2000: The Federation of Primary Care Research Networks: a national initiative to enhance networking locally. Primary Health Care Research and Development 1, 3-4.

Starfield, B. 1991: Primary care and health: a cross-national comparison. Journal of the American Medical Association 266, 2269-71.

Starfield, B. 1996: A framework for primary care research. Journal of Family Practice 42, 181-85.

Sullivan, F.M., Lewison, G. and Clarkson, J. 2002: What Scottish primary care researchers are doing to recover their standing in the UK. Health Bulletin 60, 1-4.

Svab, I., Yaphe, Y., Correia de Sousa, J. and Passerine, G. 1999: An international course for faculty development in family medicine: the Slovenian model. Medical Education 33, 780-81.

Thomas, P., Griffiths, F., Kai, J. and O'Dwyer, A. 2001: Networks for research in primary care. British Medical Journal $1322,588-90$.

Tilyard, M. and Dovey, S. 2002: Research in general practice or general practice research. New Zealand Medical Journal $113,50-52$.

Usman, H.R., Akhtar, S., Rahbar, M.H., Hamid, S., Moattar, T. and Luby, S.P. 2003: Injections in health care settings: a risk factor for acute hepatitis B virus infection in Karachi, Pakistan. Epidemiology and Infection 130, 293-300.

van Weel, C., Konig-Zahn, C., Touw-Otten, F.W.M.M., Van Duijn, N.P. and Meyboom-de Jong, B. 1995: Measuring functional health status with the COOP/WONCA charts. Groningen: Northern Centre for Health Care Research. NCH series No. 7.

van Weel, C. 1999: International research and the discipline of family medicine. European Journal of General Practice 5, $110-15$.

van Weel, C. 2003: The Brisbane Initiative: pursuing advanced research training and the establishment of a future research leadership for primary care. http://www.globalfamilydoctor. com (retrieved 14 January 2004).

van Weel, C. and Rosser, W.W. 2004: Improving health globally: a critical review of the necessity of family medicine research and recommendations to build research capacity. Annals of Family Medicine 2 (Suppl 2), S5-S16.

van Weel, C., Smith, H. and Beasley, J.W. 2000: Family practice research networks: Experiences from 3 countries. Journal of Family Practice 49, 938-943.

White, F., Rahbar, M.H., Agboatwalla, M., Luby, S., Iqbal, A. and Hozhabri, S. 2001: Elevated blood lead levels in Karachi children. Bulletin of the World Health Organization 79, 173.

Wilson, S. 2004: Primary care research networks: what do they offer? Research Policy and Planning 21, 51-57.

World Health Organization. 2003: Primary health care: a framework for future strategic directions. Geneva: World Health Organization.

Wyke, S., Bond, C., Morrison, J., Ryan, K. and Sullivan, F. 2000: Research priorities in primary care. A report from the CSO's primary care implementation committee. Health Bulletin 59, 5. 
Copyright of Primary Health Care Research \& Development is the property of Arnold Publishers and its content may not be copied or emailed to multiple sites or posted to a listserv without the copyright holder's express written permission. However, users may print, download, or email articles for individual use. 